\title{
Improvement of Medium Composition and Utilization of Mixotrophic Cultivation for Green and Blue Green Microalgae towards Biodiesel Production
}

\author{
Seham M. Hamed ${ }^{1}$, Gerd Klöck ${ }^{2 *}$ \\ ${ }^{1}$ Microbiology Department, Soils, Water and Environment Institute, Agricultural Research Center, Giza, Egypt \\ ${ }^{2}$ Biochemical Engineering, Hochschule Bremen University of Applied Sciences, Bremen, Germany \\ Email: "gerd.kloeck@hs-bremen.de
}

Received December 16, 2013; revised January 16, 2014; accepted January 23, 2014

Copyright (C) 2014 Seham M. Hamed, Gerd Klöck. This is an open access article distributed under the Creative Commons Attribution License, which permits unrestricted use, distribution, and reproduction in any medium, provided the original work is properly cited. In accordance of the Creative Commons Attribution License all Copyrights (C) 2014 are reserved for SCIRP and the owner of the intellectual property Seham M. Hamed, Gerd Klöck. All Copyright @ 2014 are guarded by law and by SCIRP as a guardian.

\section{ABSTRACT}

A possible source of biological material for the production of biodiesel is represented by microalgae, in particular by their lipid content. The aim of the present work was to optimize culture medium composition for improving growth and lipid content of green microalgae Chlorella sorokiniana, Scenedesmus acuminatus and blue green Cyanobacterium aponicum. Lipids were quantitatively determined by spectrofluorometric method using Nile red flurometric stain. Initially, the effect of two different medium types, Bold's and optimized culture medium (OCM), four types of carbon source (glucose and sodium acetate, molasses, glycerol, control) and four nitrogen concentrations $(100 \%,-75 \%,-50 \%,-25 \%)$ on the enhancement of biomass and lipid content and lipid productivity were studied; indeed, optimized culture medium significantly improved growth, CDW for three microalgae, beside increasing lipid content and lipid productivity for $S$. acuminatus and $C$. aponicum by 7.5 and 5 folds respectively at $25^{\text {th }}$ day compared to Bold's medium. Moreover, $25 \%$ nitrogen deficient medium significantly increased lipid content and lipid productivity for both $C$. sorokiniana and $C$. aponicum at $2^{\text {nd }}$ week of re-propagation to 10.6 and 2.6 folds over control (100\% nitrogen). While $S$. acuminatus recorded the significant lipid content \& productivity at $2^{\text {nd }}$ week under recommended nitrogen dose in medium $(100 \% \mathrm{~N})$ by 4.4 folds over $25 \%$ deficient medium. Meanwhile $0.3 \%$ glycerol medium enhanced CDW, lipid content of $S$. acuminatus to 1.68 $\mathrm{gL}^{-1}$. While $C$. sorokiniana and $C$. aponicum recorded significant $\mathrm{CDW}$ under $0.3 \%$ acetate medium 1.37 and $0.76 \mathrm{gL}^{-1}$. C. aponicum exhibited no growth under glycerol medium. The highest lipid content and lipid productivity were obtained under glycerol medium for $C$. sorokiniana and $S$. acuminatus $\left(64.3\right.$ and $52.8 \mathrm{mg}^{-1} \mathrm{~g}^{-1}$ and 5.4 , $\left.4.4 \mathrm{mg} \cdot \mathrm{g}^{-1} \cdot \mathrm{d}^{-1}\right)$.

\section{KEYWORDS}

Green Microalgae; Cyanobacteria; Mixotrophy; Lipid Productivity; Biomass; Biodiesel; Photobioreactor

\section{Introduction}

Microalgae display high areal productivity, and some of them are able to accumulate significant amounts of lipids. They are therefore seen as promising candidates for the industrial production of biodiesel [1]. To expand this novel feedstock, research and development is needed in several domains, from the selection of suitable strains to the optimization of the different steps required for mass

\footnotetext{
*Corresponding author.
}

scale operation (biomass production, harvesting, lipid extraction) [1]. The first step in developing an algal process is to choose the suited algal species [2]. Fast growth promotes high biomass productivity which consequently increases yield per harvest volume in a certain period (productivity) and decreases cost. The green algae are very good candidates for biodiesel production due to their characteristics such as relatively fast-growth, ease of isolation, and the ability to adapt to diverse natural habitats [3]. Quality, quantity and productivity of lipid 
are obviously of primary relevance. They depend not only on the strains, but also on culture conditions; for example, it is well known that nitrate starvation can trigger lipid accumulation, especially triacylglycerols (TAGs) suitable for biodiesel production [3-5]. Furthermore, microalgae specialized cultivation can stimulate changes in metabolism, thereby providing a simple method of enriching biomass with a target metabolite [6]. Where some algal species can utilize organic carbon sources such as glucose to produce organic molecules [7]. Mixotrophic growth is one potential mode for mass culture of microalgae and cyanobacteria particularly suitable for the production of high value bioactive compounds and fine chemicals [8]. [9] reported that about 15\% - 19\% higher growth was obtained in the mixotrophic culture. Furthermore, [8] recorded that, glucose improved the specific growth rate under mixotrophic conditions $\left(0.38 \mathrm{~d}^{-1}\right)$ was being 1.6-fold of that photoautotrophic. The idea for using biodiesel-derived crude glycerol as a carbon source for cultivation of oil producing microalgae was to provide biodiesel producers with a method of disposal for their waste glycerol and costly cheap carbon source (Figure 1). Similarly utilization of molasses hydrolysate where its utilizing alone may support rapid growth and high oil yield of Chlorella protothecoides [10].

\section{Material and Methods}

\subsection{Algae Strains}

The cyanobacterial strain Cyanobacterium aponicum and green microalgal species Chlorella sorokiniana and Scenedesmus acuminatus were obtained by prof. Gerd Klöck (Culture Collection of Algae at Hochschule Bremen University, Germany) was cultivated axenically as batch cultures in $500 \mathrm{ml}$ Erlenmeyer flasks with 1\% Wuxal medium $+0.05 \% \mathrm{MgSO}_{4} \cdot 7 \mathrm{H}_{2} \mathrm{O}$.

\subsection{Cullture System}

The effect of different media namely Bold's Basal Me-

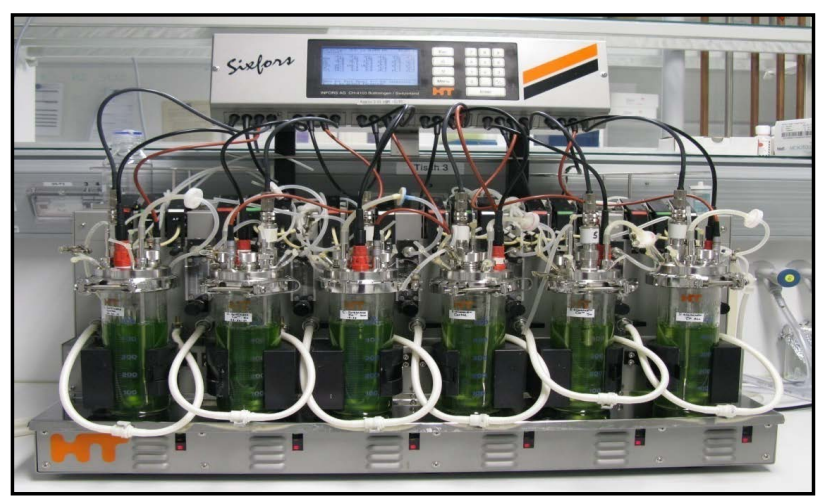

Figure 1. Mixotrophic cultivation in Sixfors photobioreactor of tested microalgal species.
dium-BBM [11]. and optimized culture medium (OCM) as described by [12]; $\mathrm{KNO}_{3}(1 \mathrm{~g} / \mathrm{L}), \mathrm{KH}_{2} \mathrm{PO}_{4}(0.075 \mathrm{~g} / \mathrm{L})$, $\mathrm{K}_{2} \mathrm{HPO}_{4}(0.1 \mathrm{~g} / \mathrm{L}), \mathrm{MgSO}_{4} \cdot 7 \mathrm{H}_{2} \mathrm{O}(0.5 \mathrm{~g} / \mathrm{L})$, $\mathrm{Ca}\left(\mathrm{NO}_{3}\right)_{2} \cdot 4 \mathrm{H}_{2} \mathrm{O}(0.0625 \mathrm{~g} / \mathrm{L}), \mathrm{FeSO}_{4} \cdot 7 \mathrm{H}_{2} \mathrm{O}(0.01 \mathrm{~g} / \mathrm{L})$, $\mathrm{H}_{3} \mathrm{BO}_{3}(0.00286 \mathrm{~g} / \mathrm{L}), \mathrm{MnCl}_{2} \cdot 4 \mathrm{H}_{2} \mathrm{O}(0.00181 \mathrm{~g} / \mathrm{L}), \mathrm{ZnCl}_{2}$ $(0.000105 \mathrm{~g} / \mathrm{L}), \mathrm{Na}_{2} \mathrm{MoO}_{4} \cdot 2 \mathrm{H}_{2} \mathrm{O}(0.000039 \mathrm{~g} / \mathrm{L})$,

$\mathrm{CuSO}_{4} \cdot 5 \mathrm{H}_{2} \mathrm{O}(0.000079 \mathrm{~g} / \mathrm{L})$ and $\mathrm{CoCl}_{2}(0.000030 \mathrm{~g} / \mathrm{L})$. Were performed in $250 \mathrm{~mL}$ Erlenmeyer flasks containing $100 \mathrm{~mL}$ medium. The sterile flasks were inoculated with $10 \mathrm{~mL}$ of a standard inoculum and cultures were illuminated by tubular fluorescent lamps (PHILIPS Master TL-D $85 \mathrm{~W} / 840$ ). The light intensity at the surface of the culturing vessels was $100 \mu \mathrm{mol}$ photons $\mathrm{m}^{-2} \cdot \mathrm{s}^{-1}$ with a photoperiod of $16: 8 \mathrm{~h}$ light: dark at $25^{\circ} \mathrm{C} \pm 2^{\circ} \mathrm{C}$, agitated at $120 \mathrm{rpm}$ in orbital incubator shaker.

\subsection{Nitrogen Deficiency}

For the nitrogen deficiency trial, the microalgal strains were inoculated in $500 \mathrm{~mL}$ Erlenmeyer flasks containing 200 OCM medium and incubated with $120 \mathrm{rpm}$ agitation at $25^{\circ} \mathrm{C} \pm 2^{\circ} \mathrm{C}$ under $100 \mu$ mol photons $\mathrm{m}^{-2} \cdot \mathrm{s}^{-1}$ light intensity with 16:8 h light and dark cycles for 7 days. The culture was then centrifuged at $4000 \mathrm{rpm}$ g for 15 min using SORVALL RC PLUS roter SLA-3000). Cell pellets were re-suspended in OCM medium (a nitrogen-rich condition $100 \%$ ) and OCM medium with different nitrogen-deficient concentrations $-75 \%,-50 \%$, $-25 \%)$. The culture was incubated for 21 days. The dry biomass and lipid content were measured for three repetitive weeks. All the experiments were carried out in at least triplicates.

\subsection{Mixotrophic Cultivation}

Was carried out by two phase growth in closed system. In the first phase of culture of C.sorokiniana, S.acuminatus and $C$. aponicum were grown photoautotrophically in a $2 \mathrm{~L}$ vessel containing $1300 \mathrm{ml}$ OCM medium, inoculated by $130 \mathrm{ml}$ of an axenic culture, in exponential growth phase, The culture was kept at $25^{\circ} \mathrm{C} \pm 2^{\circ} \mathrm{C}$ under $120 \mathrm{rpm}$ agitation, $100 \mu \mathrm{mol}$ photons $\mathrm{m}^{-2} \cdot \mathrm{s}^{-1}$ light intensity with 16:8 h light and dark cycles for 10 days. 250 $\mathrm{ml}$ of culture suspension was collected from the culture vessels and centrifuged at $5000 \mathrm{rpm}$ for 15 min under sterilized condition micro algal pellets were placed into $500 \mathrm{ml}$ culture flasks units of Sixfors photobioreactor INFORSAG-CH4103 Bottmingen Switzerland filled with OCM medium and enriched with different carbon sources types source [control $\left(0 \mathrm{gL}^{-1}\right)$, glucose $0.3 \%(\mathrm{w} / \mathrm{v})$, Sodium Acetate $0.3 \%(\mathrm{w} / \mathrm{v})$, molasses hydroyzate $0.3 \%$ $(\mathrm{v} / \mathrm{v})$ and glycerol $0.3 \%(\mathrm{v} / \mathrm{v})]$. All were illuminated by tubular fluorescent lamps (PHILIPS Master TL-D 85 W/840). The light intensity at the surface of the culturing vessels was $100 \mu \mathrm{mol}$ photons $\mathrm{m}^{-2} \cdot \mathrm{s}^{-1}$ with a photope- 
riod of 16:8 h light: dark. Stirring speed, internal temperature, $\mathrm{pH}$ and dissolved oxygen were kept constant in all photobioreactor units and it could be adjusted automatically (150 rpm, $25^{\circ} \mathrm{C} \pm 1{ }^{\circ} \mathrm{C}, 7$ and $90 \%-100 \%$ dissolved oxygen).

\subsection{Preparation of Molasses Hydrolysate}

Molasses of sugar cane was obtained from healthy shop food; it was hydrolyzed by the method described by [10]. Molasses was diluted with distilled water at a ratio of 1:1.5 (v/v). The diluted molasses was boiled for $20 \mathrm{~min}$ to remove precipitations by centrifugation at $6000 \mathrm{rpm}$ for $2 \mathrm{~min}$. The supernatant was saved for enzymatic hydrolysis by MAXINVERT200000MG $\beta$-invertase. The mixtures of molasses and invertase at a ratio of 2500:1 (w/w) were incubated at $60^{\circ} \mathrm{C}$ for $24 \mathrm{~h}$ to generate molasses hydrolysate with more reducing sugar.

\section{Analytical Procedure}

\subsection{Cell Counting}

The microalgae cell number per $\mathrm{ml}$ of $C$. aponicum, $C$. sorokiniana and $S$. acuminatus were recorded daily and determined using Neubauer haemocytometer.

\subsection{Biomass Assay}

Were precisely determined with the dry cell weight method by filtering definite volume of the cultural broth in Whatman Gf6 glass fiber filter $47 \mathrm{~mm}$ under vacuum pump N820.3ft.40.18, washing twice with double distilled water and then drying the cell pellet at $105^{\circ} \mathrm{C}$ till constant weigh.

\subsection{Lipid Assay}

Total neutral lipid content was quantitatively determined by a standard addition method, as described by [13]. Then fluorometric staining using Nile red, avoiding the association of traditional neutral lipids quantification methods to the fluorometric determination. After the optimization of instrument parameters and staining conditions, a linear correlation between the fluorescence intensity of each sample stained with the Nile red and its neutral lipids content was deduced with the standard addition method. The spectrofluorometric determinations were performed using a spectrofluorophotometer F-2500 (Hitachi). The fluorescence of the samples was always measured before and after Nile red addition, in order to subtract the intrinsic fluorescence value of the sample. Moreover, fluorescence intensity of Nile red-stained medium alone was subtracted. Samples of stained with Nile red and spiked with lipid standard. As lipid standard, a $10 \mathrm{mg} / \mathrm{ml}$ isopropanol solution of Triolein (1,2,3-Tri (cis-9-octadecenoyl)glycerol) (Sigma-Aldrich) was used.
Stock solution of Nile red (9-diethylamino-5H-benzo[[a] phenoxa-] phenoxazine-5-one) was prepared dissolving $0.5 \mathrm{mg}$ of Nile red per $\mathrm{ml}$ in acetone.

\section{Results}

According to data in Figure 2 it is obvious that OCM medium is significantly enhanced growth represented as cell number of three tested microalgal species for 22 days of incubation.

Further studying of the effect of two media type Bold's medium and OCM (present in Table 1), revealed that OCM media significantly enhanced CDW of three tested microalgal species in comparison with Bold's medium. The highest CDW was obtained on the $20^{\text {th }}$ day of incubation for $C$. aponicum and C. sorokiniana, increasing 2.2 and 1.8 folds respectively, over Bold's medium while the highest CDW for $S$. acuminatus was obtained on the $25^{\text {th }}$ day by 1.5 folds increase compared to Bold's medium at same day.

Similarly, OCM medium significantly enhanced lipid content for both $S$. acuminatus and $C$. aponicumon the $25^{\text {th }}$ day of incubation by 7.6 and 5 folds respectively compared to Bold's medium at same day. But the highest lipid content for $C$. sorokiniana was achieved under Bold's medium on the $25^{\text {th }}$ day by 1.8 fold increase. Meanwhile, S. acuminatus under OCM medium on the $25^{\text {th }}$ day recorded a highly significant lipid content compared to other tested microalgae. With respect to lipid productivity generally, the highest values of lipid productivities was achieved at exponential phases for three tested microalgae; $C$. sorokiniana recorded the highest lipid productivity $13.8 \mathrm{mg} \cdot \mathrm{g}^{-1} \cdot \mathrm{d}^{-1}$ followed by $S$. acuminatus $9.1 \mathrm{mg} \cdot \mathrm{g}^{-1} \cdot \mathrm{d}^{-1}$ under Bold's medium then they began to decline to its lowest values on the $25^{\text {th }}$ day.

OCM medium was selected for further study in which four nitrogen descending levels at three repetitive weeks of second phase propagation and study their affect on CDW, lipid content and lipid productivity. All three tested microalgae recorded high CDW at $4^{\text {th }}$ week of propagation under $100 \%$ nitrogen. S. acuminatus was the highest one $0.55 \mathrm{gL}^{-1}$. While $25 \%$ nitrogen deficient medium significantly decreased CDW for all. On the other hand it significantly increased lipid content and lipid productivity for both $C$. sorokiniana and $C$. aponicumat $2^{\text {nd }}$ week of re-propagation to 10.6 and 2.6 folds over control (100\% nitrogen). In contrast S.acuminatus recorded the significant lipid content $\&$ productivity at $2^{\text {nd }}$ week under recommended nitrogen dose in medium $(100 \% \mathrm{~N})$ by 4.4 folds over $25 \%$ deficient medium. It seems from data in Table 2 that lipid accumulation in algae cells vary according to species type, nitrogen level and incubation period.

Figure 3 shows effect of different types of carbon sources on CDW, lipid content and lipid productivity 


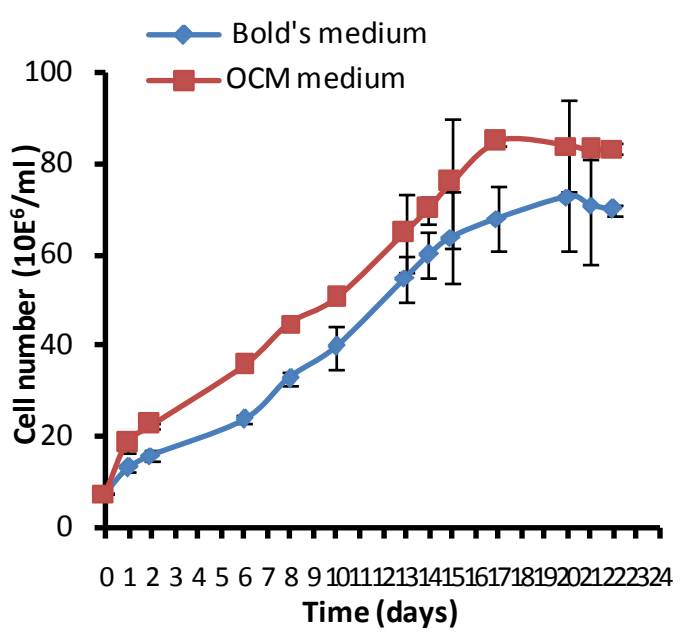

(a)

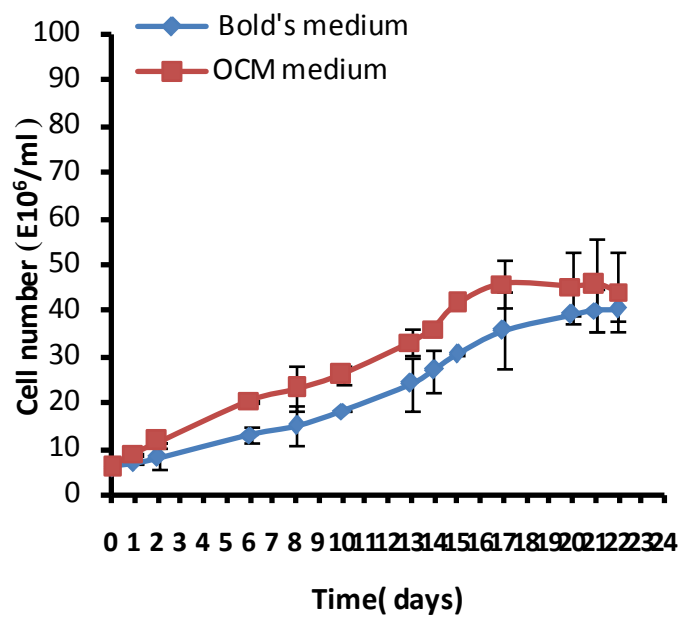

(b)

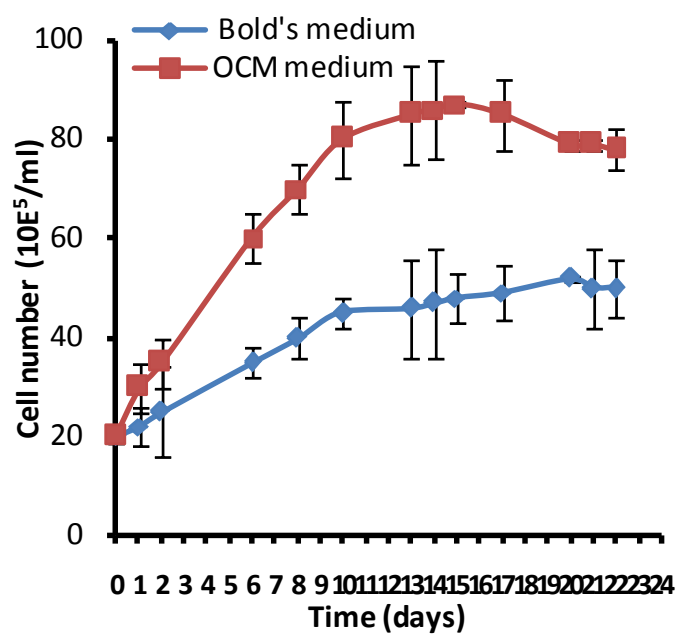

(c)

Figure 2. Effect of two different media type (Basal Bold's medium and optimized culture medium on growth of (a) Cyanobacterium aponicum; (b) Chlorella sorokiniana; (c) Scenedesmus acuminatus. Errors bars denote standard deviations among replicates.

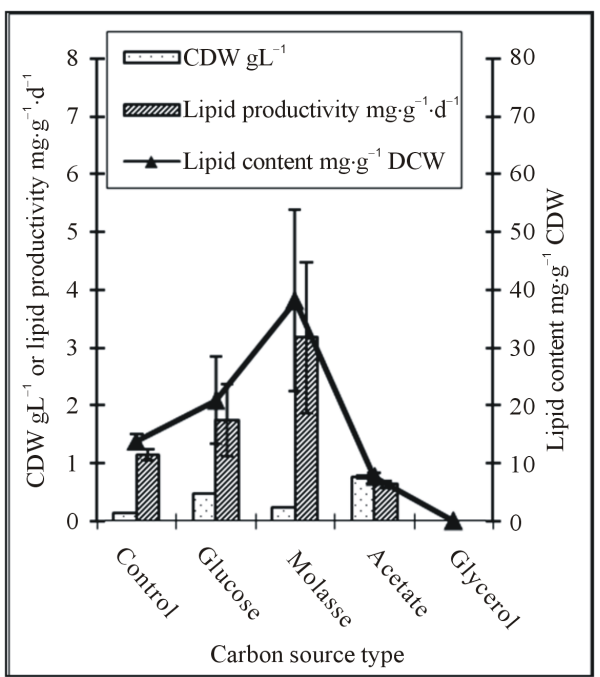

(a)

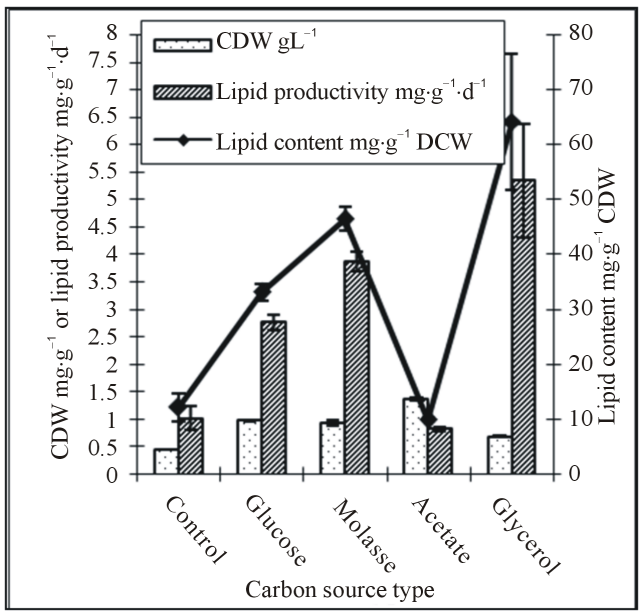

(b)

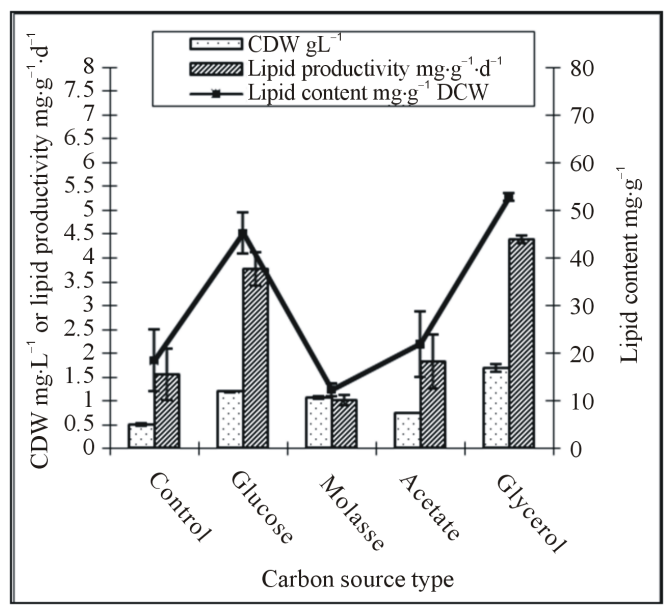

(c)

Figure 3. Effect of different carbon sources on Biomass content $\left(\mathrm{g} \cdot \mathrm{CDW} \cdot \mathrm{L}^{-1}\right)$, Lipid content $\left(\mathrm{mg} \cdot \mathrm{g}^{-1} \mathrm{CDW}\right)$ and lipid productivities $\left(\mathrm{mg}^{\circ} \mathrm{g}^{-1} \cdot \mathrm{d}^{-1}\right)$ of (a) Cyanbacterium aponicum, (b) Chlorella sorokiniana and (c) Scenedes musacuminatus. 
Table 1. Biomass content $\left(\mathrm{g} \cdot \mathrm{CDW} \cdot \mathrm{L}^{-1}\right)$, Lipid content $\left(\mathrm{mg} \cdot \mathrm{g}^{-1} \mathrm{CDW}\right)$ and lipid productivities $\left(\mathrm{mg} \cdot \mathrm{g}^{-1} \cdot \mathrm{d}^{-1}\right)$ of Cyanobacterium aponicum, Chlorella sorokiniana and Scenedesmus acuminatus under two different media types.

\begin{tabular}{|c|c|c|c|c|c|c|}
\hline Time & \multicolumn{2}{|c|}{ Cyanobacterium aponicum } & \multicolumn{2}{|c|}{ Chlorella sorokiniana } & \multicolumn{2}{|c|}{ Scenedesmus acuminatus } \\
\hline \multicolumn{7}{|c|}{ Biomass Content CDW gL ${ }^{-1}$} \\
\hline & Bold & OCM & Bold & OCM & Bold & OCM \\
\hline 0 & $0.04 \pm 0.01$ & $0.04 \pm 0.01$ & $0.06 \pm 0.01$ & $0.06 \pm 0.01$ & $0.05 \pm 0.01$ & $0.05 \pm 0.01$ \\
\hline 5 & $0.17 \pm 0.03$ & $0.21 \pm 0.03$ & $0.13 \pm 0.02$ & $0.27 \pm 0.04$ & $0.12 \pm 0.02$ & $0.23 \pm 0.03$ \\
\hline 10 & $0.50 \pm 0.20$ & $0.53 \pm 0.02$ & $0.41 \pm 0.04$ & $0.68 \pm 0.02$ & $0.34 \pm 0.03$ & $0.53 \pm 0.02$ \\
\hline 15 & $0.59 \pm 0.01$ & $0.75 \pm 0.05$ & $0.75 \pm 0.04$ & $1.16 \pm 0.04$ & $0.63 \pm 0.02$ & $0.76 \pm 0.04$ \\
\hline 20 & $0.49 \pm 0.01$ & $1.1 \pm 0.04$ & $0.65 \pm 0.05$ & $1.16 \pm 0.04$ & $1.10 \pm 0.01$ & $1.38 \pm 0.03$ \\
\hline 25 & $0.45 \pm 0.05$ & $0.95 \pm 0.05$ & $0.73 \pm 0.02$ & $0.92 \pm 0.02$ & $1.00 \pm 0.2$ & $1.46 \pm 0.04$ \\
\hline L.S.D & 0.07 & 0.03 & 0.03 & 0.03 & 0.07 & 0.02 \\
\hline \multicolumn{7}{|c|}{ Lipid content $\mathrm{mg} \cdot \mathrm{g}^{-1} \mathrm{DCW}$} \\
\hline 0 & $10.7 \pm 1.15$ & $10.7 \pm 1.15$ & $15.0 \pm 5.00$ & $15 \pm 5.00$ & $30 \pm 10$ & $30 \pm 10$ \\
\hline 5 & $17.8 \pm 0.20$ & $19.4 \pm 0.55$ & $69.2 \pm 7.69$ & $42.6 \pm 4.79$ & $45.6 \pm 4.19$ & $23.9 \pm 2.17$ \\
\hline 10 & $17.0 \pm 3.00$ & $30.1 \pm 1.89$ & $50.0 \pm 8.54$ & $38.8 \pm 6.61$ & $26.3 \pm 5.89$ & $10.5 \pm 1.08$ \\
\hline 15 & $11.3 \pm 1.01$ & $27.3 \pm 4.16$ & $62.7 \pm 4.00$ & $40.7 \pm 2.60$ & $21.5 \pm 2.46$ & $10.2 \pm 3.43$ \\
\hline 20 & $22.6 \pm 2.06$ & $42.5 \pm 8.74$ & $70.0 \pm 2.31$ & $39.5 \pm 1.37$ & $30.8 \pm 7.79$ & $37.0 \pm 8.99$ \\
\hline 25 & $9.7 \pm 3.38$ & $48.6 \pm 6.48$ & $41.1 \pm 2.74$ & $32.4 \pm 2.20$ & $14.3 \pm 5.51$ & $108.6 \pm 7.55$ \\
\hline L.S.D & 1.74 & 3.95 & 4.54 & 3.42 & 5.27 & 5.33 \\
\hline \multicolumn{7}{|c|}{ Lipid productivity $\mathrm{mg} \cdot \mathrm{g}^{-1} \cdot \mathrm{d}^{-1}$} \\
\hline 5 & $3.55 \pm 0.04$ & $3.87 \pm 0.11$ & $13.83 \pm 1.54$ & $8.51 \pm 0.96$ & $9.11 \pm 0.84$ & $4.79 \pm 0.43$ \\
\hline 10 & $1.70 \pm 0.30$ & $3.01 \pm 0.19$ & $5.00 \pm 0.85$ & $3.88 \pm 0.66$ & $2.63 \pm 0.59$ & $1.05 \pm 0.11$ \\
\hline 15 & $0.76 \pm 0.07$ & $1.82 \pm 0.28$ & $4.18 \pm 0.27$ & $2.71 \pm 0.17$ & $1.43 \pm 0.16$ & $0.68 \pm 0.23$ \\
\hline 20 & $1.13 \pm 0.10$ & $2.12 \pm 0.44$ & $3.50 \pm 0.12$ & $1.974 \pm 0.07$ & $1.54 \pm 0.39$ & $1.85 \pm 0.45$ \\
\hline 25 & $0.39 \pm 0.14$ & $1.95 \pm 0.26$ & $1.64 \pm 0.11$ & $1.29 \pm 0.09$ & $0.57 \pm 0.22$ & $4.34 \pm 0.30$ \\
\hline L.S.D & 0.13 & 0.23 & 0.65 & 0.43 & 0.41 & 0.27 \\
\hline
\end{tabular}

Each value is the mean of three readings \pm standard deviation at $\mathrm{P} \leq 0.05$ using one way analysis of variance (ANOVA) L.S.D is least significant difference.

Table 2. Biomass content $\left(\mathrm{g} \cdot \mathrm{CDW} \cdot \mathrm{L}^{-1}\right)$, Lipid content $\left(\mathrm{mg} \cdot \mathrm{g}^{-1} \mathrm{CDW}\right)$ and lipid productivities $\left(\mathrm{mg} \cdot \mathrm{L}^{-1} \cdot \mathrm{d}^{-1}\right)$ of Cyanobacterium aponicum, Chlorella sorokiniana and Scenedesmus acuminatus under four levels of nitrogen deficiency of OCM medium.

\begin{tabular}{|c|c|c|c|c|c|c|c|c|c|}
\hline \multicolumn{10}{|c|}{ Cyanobacterium aponicum } \\
\hline \multirow{2}{*}{$\begin{array}{l}\text { Nitrogen } \\
\text { level }\end{array}$} & \multicolumn{3}{|c|}{ Biomass Content CDW gL ${ }^{-1}$} & \multicolumn{3}{|c|}{ Lipid content $\mathrm{mg} \cdot \mathrm{g}^{-1} \mathrm{DCW}$} & \multicolumn{3}{|c|}{ Lipid productivity $\mathrm{mg} \cdot \mathrm{g}^{-1} \cdot \mathrm{d}^{-1}$} \\
\hline & $2^{\text {nd }}$ week & $3^{\text {rd }}$ week & $4^{\text {th }}$ week & $2^{\text {nd }}$ week & $3^{\text {rd }}$ week & $4^{\text {th }}$ week & $2^{\text {nd }}$ week & $3^{\text {rd }}$ week & $4^{\text {th }}$ week \\
\hline $100 \%$ & $0.22 \pm 0.02$ & $0.32 \pm 0.01$ & $0.45 \pm 0.02$ & $6.81 \pm 0.20$ & $18.25 \pm 0.07$ & $15.52 \pm 0.50$ & $0.97 \pm 0.03$ & $1.34 \pm 0.25$ & $0.74 \pm 0.26$ \\
\hline $75 \%$ & $0.25 \pm 0.03$ & $0.47 \pm 0.03$ & $0.44 \pm 0.06$ & $2.00 \pm 0.05$ & $8.50 \pm 1.00$ & $11.45 \pm 0.51$ & $0.28 \pm 0.02$ & $0.61 \pm 0.11$ & $0.55 \pm 0.05$ \\
\hline $50 \%$ & $0.19 \pm 0.01$ & $0.40 \pm 0.02$ & $0.42 \pm 0.01$ & $2.64 \pm 0.04$ & $7.50 \pm 0.50$ & $11.93 \pm 0.06$ & $0.37 \pm 0.03$ & $0.54 \pm 0.07$ & $0.56 \pm 0.04$ \\
\hline $25 \%$ & $0.18 \pm 0.02$ & $0.37 \pm 0.02$ & $0.41 \pm 0.01$ & $19.41 \pm 0.06$ & $19.25 \pm 1.01$ & $9.66 \pm 0.35$ & $2.76 \pm 0.45$ & $1.35 \pm 0.05$ & $0.46 \pm 0.01$ \\
\hline L.S.D & 0.02 & 0.02 & 0.03 & 0.36 & 0.68 & 0.32 & 0.18 & 0.12 & 0.11 \\
\hline \multicolumn{10}{|c|}{ Chlorella sorokiniana } \\
\hline $100 \%$ & $0.37 \pm 0.03$ & $0.42 \pm 0.02$ & $0.47 \pm 0.01$ & $4.01 \pm 1.00$ & $18.78 \pm 0.90$ & $12.79 \pm 2.20$ & $0.57 \pm 0.03$ & $1.35 \pm 0.25$ & $0.60 \pm 0.15$ \\
\hline $75 \%$ & $0.35 \pm 0.05$ & $0.39 \pm 0.01$ & $0.47 \pm 0.03$ & $11.44 \pm 0.55$ & $8.50 \pm 1.00$ & $19.15 \pm 0.85$ & $1.64 \pm 0.45$ & $0.61 \pm 0.11$ & $0.92 \pm 0.08$ \\
\hline $50 \%$ & $0.26 \pm 0.04$ & $0.4 \pm 0.02$ & $0.45 \pm 0.02$ & $26.97 \pm 3.00$ & $7.50 \pm 0.50$ & $6.67 \pm 0.33$ & $3.83 \pm 0.28$ & $0.54 \pm 0.07$ & $0.32 \pm 0.11$ \\
\hline $25 \%$ & $0.26 \pm 0.10$ & $0.42 \pm 0.07$ & $0.44 \pm 0.02$ & $42.34 \pm 2.65$ & $18.94 \pm 1.05$ & $22.74 \pm 2.25$ & $6.01 \pm 0.50$ & $1.35 \pm 0.05$ & $1.10 \pm 0.19$ \\
\hline L.S.D & 0.05 & 0.03 & 0.02 & 1.69 & 0.73 & 1.34 & 0.29 & 0.12 & 0.12 \\
\hline \multicolumn{10}{|c|}{ Scenedes musacuminatus } \\
\hline $100 \%$ & $0.29 \pm 0.01$ & $0.46 \pm 0.02$ & $0.55 \pm 0.05$ & $27.53 \pm 3.00$ & $13.01 \pm 1.50$ & $10.90 \pm 3.60$ & $3.95 \pm 0.05$ & $0.94 \pm 0.04$ & $0.52 \pm 0.08$ \\
\hline $75 \%$ & $0.24 \pm 0.06$ & $0.44 \pm 0.02$ & $0.47 \pm 0.03$ & $20.88 \pm 1.40$ & $5.69 \pm 0.90$ & $8.69 \pm 0.30$ & $2.93 \pm 0.50$ & $0.40 \pm 0.10$ & $0.41 \pm 0.11$ \\
\hline $50 \%$ & $0.22 \pm 0.03$ & $0.45 \pm 0.03$ & $0.47 \pm 0.04$ & $20.45 \pm 1.95$ & $8.89 \pm 0.30$ & $8.50 \pm 0.60$ & $2.92 \pm 0.18$ & $0.63 \pm 0.03$ & $0.41 \pm 0.02$ \\
\hline $25 \%$ & $0.16 \pm 0.03$ & $0.27 \pm 0.04$ & $0.29 \pm 0.01$ & $6.25 \pm 1.05$ & $7.69 \pm 0.30$ & $10.45 \pm 2.50$ & $0.89 \pm 0.05$ & $0.55 \pm 0.15$ & $0.49 \pm 0.01$ \\
\hline L.S.D & 0.03 & 0.02 & 0.03 & 1.63 & 0.73 & 1.81 & 0.22 & 0.08 & 0.05 \\
\hline
\end{tabular}

Each value is the mean of three readings \pm standard deviation at $\mathrm{P} \leq 0.05$ using one way analysis of variance (ANOVA) L.S.D is least significant difference. 
during 12 days of incubation. Generally mixotrophic cultivation enhanced both CDW and lipid content for three microalgae but response of each one towards carbon source type markedly varied. S. acuminatus recorded highly significant CDW under $0.3 \%$ (v/v) glycerol medium $1.68 \mathrm{~g} \cdot \mathrm{L}^{-1}$ by increasing 3.4 folds over control while $C$. sorokiniana and C. aponicum recorded significant CDW under acetate medium 1.37 and $0.7 \mathrm{~g} \cdot \mathrm{L}^{-1}$ by increasing 2.9 and 5.8 folds respectively over control. $C$. aponicum exhibited no growth under $0.3 \%$ (v/v) glycerol medium.

Evaluation of lipid content revealed that C. sorokinia$n a$ recorded the highest lipid content under glycerol medium $64.3 \mathrm{mg} \cdot \mathrm{g}^{-1}$ followed by S.acuminatus $52.8 \mathrm{mg} \cdot \mathrm{g}^{-1}$ by increasing 5.2 and 2.8 folds respectively over control. In contrast C. aponicum reached its high lipid content under molasses medium $38.13 \mathrm{mg} \cdot \mathrm{g}^{-1}$. The lowest lipid content was obtained by acetate medium for $C$. sorokiniana and C. aponicum with significant decrease of 1.2 and 1.8 folds under control medium.

With respect to lipid productivity $C$. sorokiniana recorded the highest value $5.4 \mathrm{mg} \cdot \mathrm{g}^{-1} \cdot \mathrm{d}^{-1}$ followed by S.acuminatus $4.4 \mathrm{mg} \cdot \mathrm{g}^{-1} \cdot \mathrm{d}^{-1}$ while C. aponicum showed $3.18 \mathrm{mg} \cdot \mathrm{g}^{-1} \cdot \mathrm{d}^{-1}$ under molasses medium.

\section{Discussion}

For biodiesel production, biomass productivity and lipid content play an important role from the economic point of view. The obtained results showed that OCM medium significantly improved growth of the three tested microalgae compared to Bold's medium this finding is in accordance with [14], who reported that a proper medium design has shown to have a large impact on the growth capacity of Chlorella vulgaris cultures. On the other hand OCM medium enhanced lipid content for both $S$. acuminatus and $C$. aponicumat $25^{\text {th }}$ day of incubation by 7.6 and 5 folds respectively this finding is in accordance [15], who mentioned that Lipid composition and productivity of microalgae depend on growth conditions such as medium composition, irradiance and temperature. With respect to the effect of nitrogen starvation on growth, lipid content and lipid productivity of C. aponicum, C. sorokiniana and S. acuminatus, the obtained results in (Table 2) showed that 25\% nitrogen deficient medium significantly reduces the growth of three microalgae and markedlyincrease in lipid content of $C$. sorokiniana and C. aponicum. The reduction in growth by nitrogen deficiency may be explained by the observations of $[16,17]$ who found that the decrease in pigment contents and photosynthesis are a typical response in nitrogen-limited algae. [18] made a comparative study between chlorophyll content of groups of green algae and cyanobacteria with different nitrogen concentrations; they showed that chlorophyll contents decreased with decreasing nitrogen concentrations. They also concluded that, with decreasing nitrogen levels, the chlorophyll contents of the cells dropped indicating a rapid reduction or even breakdown of the whole chloroplast apparatus and consequently decreasing of growth. The increase in lipid content observed in the present study as a result of nitrogen deficiency is in agreement with [18-20]. They reported that microalgae produce a considerable amount of lipid when exposed to environmental stress such as nitrogen limitation. The possible reason could be that under nitrogen deficiency the rest of available nitrogen is utilized for synthesis of enzymes and essential cell structures. Any carbon dioxide subsequently fixed is therefore converted into carbohydrate or lipid rather than protein [21]. As indicated from present results in (Figure 3), the addition of a carbon source caused marked increase in CDW, lipid content and lipid productivity for all tested species compared to the control. One interesting result, S. acuminatus, recorded the highest CDW under glycerol $0.3 \%(\mathrm{v} / \mathrm{v})$ medium, while the same concentration inhibited the growth of C. aponicum. Moreover, a glycerol medium significantly enhanced lipid content and lipid productivity of C. sorokiniana and S. acuminatus to 5.2 and 2.8 folds respectively over control this finding is in accordance with [22], who reported that addition of 0.05 and $0.1 \mathrm{M}$ of glycerol to Scenedesmus obliquus medium increased the biomass productivity by $6 \%$ and $5 \%$, respectively during 12 days of incubation. [23] reported that the addition of glycerol in the culture medium of the red alga Gratelupia doryphora caused substantial increase of the total lipid and glycolipid content, while the amount of polar lipids remained constant. In contrast, addition of $0.3 \%$ glycerol (v/v) to C. aponicum medium inhibited growth this is due to the high osmotic pressure of that carbon source to this microorganism. This finding agreed also with [22], who found that culture treated with $0.2 \mathrm{M}$ of glycerol showed inhibition of growth by $17 \%$ below the control. Although acetate medium significantly enhanced CDW for both C. sorokiniana and C. aponicum, their lipid content markedly decreased compared to control, this finding is in accordance with [24] who reported that biomass productivity and lipid content are inversely related. High lipid content microalgae cells generally show much slower growth, while those containing low lipid levels can have high growth rates $[25,26]$. In contrast molasses medium significantly enhanced lipid content and lipid productivity of C. aponicum to 2.8 folds over control after 12 days of incubation this results is agreed with [10], who reported that waste molasses hydrolysate alone may support rapid growth and high oil yield of Chlorella protothecoides. This is due to it containing both organic carbons and other nutrients. Molasses nutrients include vitamins, trace elements and many other kinds of ingredients; they consist mainly of $48 \%$ sugars $[10,27]$. 


\section{Conclusion}

A comparative study between three different microalgae chlorophyta (C.sorokiniana, S. acuminatus) and cyanobacterial species $C$. aponicum towards achieving high biomass, maximum lipid content and lipid productivity for biodiesel production. C. sorokiniana fulfils the major requirement for lipid production under OCM medium enriched with glycerol $0.3 \%(\mathrm{v} / \mathrm{v})$. Lipid content of this strain could be further increased by decreasing nitrogen to $-25 \%$. The results have proved that the modification of the culture can tailor to the specific demands of highly productive microalgae to attain a consistently good yield of lipid. With further understanding on the cultivation of C. sorokiniana in photobioreactors, much greater productivity of algal lipid would be obtained. Moreover, the use of hydrolyzed molasses, a by-product of sugar refinery, as a cheap carbon source in mixotrophic cultures of C. aponicum strain stimulated both biomass and lipid content.

\section{REFERENCES}

[1] J. Pruvost, G. Van Vooren, B. Le Gouic, A. CouzinetMossion and J. Legrand, "Systematic Investigation of Biomass and Lipid Productivity by Microalgae in Photobioreactors for Biodiesel Application,” Bioresource Technology, Vol. 102, No. 1, 2011, pp. 150-158. http://dx.doi.org/10.1016/j.biortech.2010.06.153

[2] M. J. Griffiths and S. T. L. Harrison, "Lipid Productivity as a Key Characteristic for Choosing Algal Species for Biodiesel Production,” Journal of Applied Phycology, Vol. 21, No. 5, 2009, pp.493-507. http://dx.doi.org/10.1007/s10811-008-9392-7

[3] Q. Hu, M. Sommerfeld, E. Jarvis, M. L. Ghirardi, M. Posewitz, M. Seibert and A. Darzins, "Microalgal Triacylglycerols as Feedstocks for Biofuel Production: Perspectives and Advances,” The Plant Journal for Cell and Molecular Biology, Vol. 54, No. 4, 2008, pp. 621-639. http://dx.doi.org/10.1111/j.1365-313X.2008.03492.x

[4] Y. Chisti, "Biodiesel from Microalgae,” Biotechnology Advances, Vol. 25, No. 3, 2007, pp. 294-306. http://dx.doi.org/10.1016/j.biotechadv.2007.02.001

[5] L. Rodolfi, G. Chini Zittelli, N. Bassi, G. Padovani, N. Biondi, G. Bonini and M. Tredici, "Microalgae for Oil: Strain Selection, Induction of Lipid Synthesis and Outdoor Mass Cultivation in a Low-Cost Photobioreactor," Biotechnology and Bioengineering, Vol. 102, No. 1, 2009, pp. 100-112. http://dx.doi.org/10.1002/bit.22033

[6] J. N. Rosenberg, G. A. Oyler, L. Wilkinson and M. J. Betenbaugh, “A Green Light for Engineered Algae: Redirecting Metabolism to Fuel a Biotechnology Revolution," Current Opinion in Biotechnology, Vol. 19, No. 5, 2008, pp. 430-436. http://dx.doi.org/10.1016/j.copbio.2008.07.008

[7] Y.-K. Lee, "Microalgal Mass Culture Systems and Methods: Their Limitation and Potential," Journal of Applied Phycology, Vol. 13, No. 4, 2001, pp. 307-315.
http://dx.doi.org/10.1023/A:1017560006941

[8] G. Yu, D. Shi, Z. Cai, W. Cong and F. Ouyang, "Growth and Physiological Features of Cyanobacterium Anabaena sp. Strain PCC 7120 in a Glucose-Mixotrophic Culture,” Chinese Journal of Chemical Engineering, Vol. 19, No. 1, 2011, pp. 108-115.

http://dx.doi.org/10.1016/S1004-9541(09)60185-3

[9] Y.-I. Yamane, T. Utsunomiya, M. Watanabe and K. Sasaki, "Biomass Production in Mixotrophic Culture of Euglena gracilis under Acidic Condition and Its Growth Energetic,” Biotechnology Letters, Vol. 23, No. 15, 2001, pp. 1223-1228. http://dx.doi.org/10.1023/A:1010573218863

[10] D. Yan, Y. Lu, Y.-F. Chen and Q. Wu, "Waste Molasses Alone Displaces Glucose-Based Medium for Microalgal Fermentation towards Cost-Saving Biodiesel Production," Bioresource Technology, Vol. 102, No. 11, 2011, pp. 64876493.http://dx.doi.org/10.1016/j.biortech.2011.03.036

[11] H. W. Bischoff and H. C. Bold, "Phycological Studies IV. Some Soil Algae from Enchanted Rock and Related Algal Species,” University of Texas Publication No. 6318, 1963, p. 95.

[12] T. Heredia-Arroyo, W. Wei, R. Ruan and B. Hu, "Mixotrophic Cultivation of Chlorella vulgaris and Its Potential Application for the Oil Accumulation from Non-Sugar Materials,” Biomass and Bioenrgy, Vol. 35, No. 5, 2011, pp. 2245-2253.

http://dx.doi.org/10.1016/j.biombioe.2011.02.036

[13] E. Bertozzini, L. Galluzzi, A. Penna and M. Magnani, "Application of the Standard Addition Method for the Absolute Quantification of Neutral Lipids in Microalgae Using Nile Red," Journal of Microbiological Methods, Vol. 87, No. 1, 2011, pp. 17-23.

http://dx.doi.org/10.1016/j.mimet.2011.06.018

[14] R. K. Mandalam and B. Ǿ. Palsson, "Cell Cycle of Chlorella vulgaris Can Deviate from the Synchronous Binary Division Model,” Biotechnology Letters, Vol. 19, No. 6, 1997, pp. 587-591. http://dx.doi.org/10.1023/A:1018310008826

[15] R. Huerlimann, R. de Nys and K. Heimann, "Growth, Lipid Content, Productivity, and Fatty Acid Composition of Tropical Microalgae for Scale-Up Production,” Biotechnology and Bioengineering, Vol. 107, No. 2, 2010, pp. 245-257. http://dx.doi.org/10.1002/bit.22809

[16] D. H. Turpin, "Effect of Inorganic N Availability on Algal Photosynthesis and Carbon Metabolism," Journal of Phycology, Vol. 27, No. 1, 1991, pp. 14-20. http://dx.doi.org/10.1111/j.0022-3646.1991.00014.x

[17] F. J. L. Gordillo, C. Jimenez, F. L. Figueroa and F. X. Niel, "Effect of Increased Atmospheric $\mathrm{CO}_{2}$ and $\mathrm{N}$ Supply on Photosynthesis, Growth and Cell Composition of the Cyanobacterium Spirulina platensis,” Journal of Applied Phycology, Vol. 10, No. 5, 1998, pp. 461-469. http://dx.doi.org/10.1023/A:1008090402847

[18] M. Piorreck, K.-H. Baasch and P. Pohl, "Biomass Production, Total Protein, Chlorophylls, Lipids and Fatty Acids of Fresh Water Green and Blue-Green Algae under Different Nitrogen Regimes,” Phytochemistry, Vol. 23, No. 2, 1984, pp. 207-216. 
http://dx.doi.org/10.1016/S0031-9422(00)80304-0

[19] A. M. Illman, A. H. Scragg and S. W. Shales, "Increase in Chlorella Strains Calorific Values when Grown in Low Nitrogen Medium," Enzyme and Microbial Technology, Vol. 27, No. 8, 2000, pp. 631-635. http://dx.doi.org/10.1016/S0141-0229(00)00266-0

[20] Z.-Y. Liu, G.-C. Wang and B.-C. Zhou, "Effect of Iron on Growth and Lipid Accumulation in Chlorella vulgaris," Bioresource Technology, Vol. 99, No. 11, 2008, pp. 47174722. http://dx.doi.org/10.1016/j.biortech.2007.09.073

[21] B. Richardson, D. M. Orcutt, H. A. Schwertner, L. Martinez and E. Wickline, "Effects of Nitrogen Limitation on the Growth and Composition of Unicellular Algae in Continuous Culture, " Appllied and Environmental Micobiology, Vol. 18, No. 2, 1969, pp. 245-250.

http://www.ncbi.nlm.nih.gov/pmc/articles/PMC377951/p df/applmicro00008-0123.pdf

[22] M. El-Sheekh, A. Abomohra and D. Hanelt, "Optimization of Biomass and Fatty Acid Productivity of Scenedesmus obliquus as a Promising Microalga for Biodiesel Production,” World Journal of Microbiology Biotechnology, Vol. 29, No. 5, 2012, pp. 915-922. http://dx.doi.org/10.1007/s11274-012-1248-2
[23] A. P. Ivanova, R. R. Robaina, J. Martin and K. L. Stefanov, "Effect of Glycerol on the Lipids in the Red Alga Gratelupia doryphora," Grasas Aceites, Vol. 50, No. 6, 1999, pp. 469-471. http://dx.doi.org/10.3989/gya.1999.v50.i6.696

[24] É. C. Francisco, D. B. Neves, E. Jacob-Lopes and T. T. Franco, "Microalgae as Feedstock for Biodiesel Production: Carbon Dioxide Sequestration, Lipid Production and Biofuel Quality,” Journal of Chemical Technology and Biotechnology, Vol. 85, No. 3, 2010, pp. 395-403. http://dx.doi.org/10.1002/jctb.2338

[25] M. E. Huntley and D. G. Redalje, “ $\mathrm{CO}_{2}$ Mitigtion and Renewable Oil from Photosynthetic Microbes,” Mitigation and Adaptation Strategies for Global Change, Vol. 12, No. 4, 2007, pp. 573-608. http://dx.doi.org/10.1007/s11027-006-7304-1

[26] A. Widjaja, C.-C. Chein and Y.-H. Ju, "Study of Increasing Lipid Production from Fresh Water Microalgae Chlorella vulgaris," Journal of the Taiwan Institute of Chemical Engineers, Vol. 40, No. 1, 2009, pp. 13-20. http://dx.doi.org/10.1016/j.jtice.2008.07.007

[27] W. Crueger and A. Crueger, "Biotecnologia: Manual de Microbiologia Industrial,” Zaragoza Acribia S.A., 1989. 